Thorax (1976), 31, 127.

\title{
Hypersensitivity pneumonitis after exposure to isocyanates
}

\author{
J OH N CHARLES, ALAN BER NSTEIN, \\ B R I A N J ONES, D. J. JONES, J.H. EDW ARDS, \\ R. M. E. S E A L, a n A N T HON Y S E T O N \\ Sully Hospital, Penarth and Hope Hospital, Salford
}

\begin{abstract}
Charles, J., Bernstein, A., Jones, B., Jones, D. J., Edwards, J. H., Seal, R. M. E., and Seaton, A. (1976). Thorax, 31, 127-136. Hypersensitivity pneumonitis after exposure to isocyanates. Four patients exposed to isocyanate vapour developed dyspnoea associated with restriction and reduced gas transfer as well as moderate airways obstruction on lung function testing. In one patient bilateral radiographic shadowing was present and an open lung biopsy was performed. The microscopic appearances ranged from acute inflammation to end-stage fibrosis but the centrilobular accentuation of disease and the presence of areas resembling bronchopulmonary aspergillosis suggested that the process was a hypersensitivity response to inhaled allergen. Challenge tests with albumin and toluene diisocyanate-albumin were carried out in sensitized and control rabbits. The sensitized animals developed extensive lung damage of the type associated with an Arthus reaction. It is suggested that patients exposed to isocyanates may occasionally develop a hypersensitivity pneumonitis rather than the more usual asthmatic syndrome.
\end{abstract}

Organic isocyanates are used in the manufacture of flexible and rigid foams, synthetic rubbers, adhesives, and paints. The isocyanates involved are toluene diisocyanate (TDI), diphenyl-methane diisocyanate (MDI), naphthylene diisocyanate (NDI), and hexamethylene diisocyanate (HDI). TDI is the most widely used.

Organic isocyanate vapour has been known for many years to produce irritation of the skin, eyes, and bronchial tree and also to produce sensitization resulting in bronchospasm which is often delayed some hours after exposure (Fuchs and Valade, 1951; Woodbury, 1956; Trenchard and Harris, 1963; Silver, 1963; Dodson, 1966). It also seems probable that long-term exposure to low concentrations, below the recommended threshold limit value of $0.02 \mathrm{ppm}$, may produce chronic airways obstruction (Adams, 1970; Hill, 1970; Peters, 1970).

In the large majority of reported cases of isocyanate toxicity, chest radiographs have been normal. However, Blake et al. (1965) described four patients in whom pulmonary opacities developed after isocyanate exposure.
This paper describes four patients who presented with dyspnoea after exposure to isocyanates, and in whom evidence of interstitial rather than bronchial disease was found. Challenge experiments in rabbits were carried out in an attempt to reproduce the disease, and these results are also described.

\section{METHODS}

PATIENTS Four patients were studied. Three worked in factories using TDI in the manufacture of polyurethane foam and were therefore exposed to low levels of TDI. Two of these were known to have been exposed to large 'spills' of TDI, one on three occasions. The fourth patient had used a polyurethane paint, thought to contain a low percentage of HDI, for six months.

PULMONARY FUNCTION Forced expiratory volume in one second $\left(\mathrm{FEV}_{1}\right)$ and vital capacity (VC) were determined using a dry spirometer, the residual volume $(\mathrm{RV})$, functional residual capacity (FRC), and total lung capacity (TLC) by the closed-circuit helium dilution method, and the 
gas transfer factor by the single-breath carbon monoxide technique. Static compliance was measured in the seated position using a Godard pneumotachograph with integrator for volume while oesophageal pressures were taken from a balloon sited in the lower third of the oesophagus and measured with a differential pressure transducer. Predicted values were those of Cotes (1968).

IMMUNOLOGY In case 1, TDI-albumin (prepared by the method of Scheel, Killens, and Josephson (1964)) was used to identify precipitating antibodies (Ouchterlony, 1953) and haemagglutinating antibodies using formalinized sheep red blood cells (Boyden, 1951). Precipitating antibodies to a range of common antigens were also sought. Skin testing was carried out in this patient and one control with $0.1 \mathrm{ml}$ of TDI-albumin, $1 \mathrm{mg} / \mathrm{ml}$ intradermally.

ANIMAL EXPERIMENTS Antigen preparation. TDIegg albumin conjugate was prepared by the method of Scheel et al. (1964), $40 \mathrm{mg}$ of TDI reacting with $1 \mathrm{~g}$ of protein at $10 \mathrm{mg} \mathrm{ml}^{-1}$; the conjugate was then dialysed extensively against $0.01 \mathrm{M}$ phosphate-buffered saline, $\mathrm{pH} 7.2$, and stored frozen until required.

Sensitization TDI-albumin and albumin were each emulsified in Freund's incomplete adjuvant at concentrations of $5 \mathrm{mg} \mathrm{ml}^{-1}$ of protein. Ten New Zealand white rabbits, aged 9-12 months, were sensitized to TDI-albumin by a series of intramuscular injections given twice a week over a period of three weeks, starting with $0.5 \mathrm{ml}$ of antigen in adjuvant and increasing the dose to $2.0 \mathrm{ml}$. Ten rabbits were similarly sensitized to albumin.

Serology Rabbits were bled one week after the final sensitizing dose, and sera were examined for the presence of precipitating antibodies by agar gel double diffusion (Ouchterlony, 1953); complement fixation tests (Bradstreet and Taylor, 1962) were also performed. Quantitative precipitin curves (Kabat, 1961) were obtained by incubating $0,2,4,6,8$, and $10 \mathrm{mg}$ of TDI-albumin conjugate with $1 \mathrm{ml}$ aliquots of either TDIalbumin or albumin antiserum at $37^{\circ} \mathrm{C}$ for 2 hours and at $4^{\circ} \mathrm{C}$ overnight. Similarly, precipitin curves were obtained with albumin antigen and both TDI-albumin and albumin antisera. The precipitates were collected, washed with saline, and dissolved in $0.0 \mathrm{rM} \mathrm{NaOH}$, and protein concentrations were determined by spectrophotometry at $280 \mathrm{~m} \mu, \stackrel{\overrightarrow{\vec{\rho}}}{\overrightarrow{\vec{\rho}}}$ using an absorption value of $\mathbf{1 3 . 6}$ for a $1 \%$ solution of $\gamma$ globulin (Rowe and Fahey, 1965).

Skin Testing Skin tests were performed on four of the rabbits sensitized to TDI-albumin. An area on the hind leg was shaved and $0.2 \mathrm{ml}$ of TDIalbumin $\left(1 \mathrm{mg} \mathrm{ml}^{-1}\right)$, albumin $\left(1 \mathrm{mg} \mathrm{ml}^{-1}\right)$, and saline were introduced intradermally. Control tests were performed on two unsensitized rabbits.

Challenge Two weeks after the final sensitizing dose rabbits were challenged by endotracheal deposition of antigen while under pentobarbitone sodium (Nembutal) anaesthesia.

Eight rabbits sensitized to TDI-albumin received $0.5 \mathrm{ml}$ of the same antigen at $10 \mathrm{mg} \mathrm{ml}^{-1}$ and two received $0.5 \mathrm{ml}$ of saline. Of the rabbits 은 sensitized to egg-albumin, two were challenged $\rightarrow$ endotracheally with $0.5 \mathrm{ml}$ of albumin at $10 \mathrm{mg} \frac{7}{0}$ $\mathrm{ml}^{-1}$ and two with TDI-albumin; further unsensitized control rabbits were challenged endotrache- $\vec{\varphi}$ ally with $0.5 \mathrm{ml}$ of saline, TDI-albumin, and albumin.

All rabbits were killed by a rapid intravenous injection of pentobarbitone sodium either 18 hours or six days after challenge. Lungs were removed immediately after death, inflated, and fixed with formalin, sectioned on the microtome, and stained with haematoxylin and eosin, alcian blue or periodic acid Schiff.

\section{CASE REPORTS}

CASE 1 A 50-year-old non-smoking man had worked for five years on a polyurethane foam $\dot{\sigma}$ process. He had previously been a coalminer for 3 11 years. In May 1968 he was admitted to hospital $\delta$ with a six-week history of dyspnoea, weight loss, and fever. He had no cough, sputum or wheezing. 웅 $\mathrm{He}$ was tachypnoeic, and chest radiographs showed an alveolar filling lesion, confluent in the left lung and in the right mid zone (Fig. 1). Previous radiographs, though said to be normal, were $\sigma$ unobtainable. Sputum showed a growth of Haemo- N philus influenzae of doubtful significance. Re- N peated cultures failed to grow Aspergillus, and 0 hyphae were never seen in fresh specimens. After treatment with antibiotics there was partial radio- $\frac{\stackrel{C}{\Phi}}{\mathscr{D}}$ logical resolution and he was discharged. Two $\stackrel{\infty}{\rightarrow}$ months later he remained dyspnoeic and the 0 radiograph then showed shadowing in the right ${ }_{0}$ lower zone (Fig. 2). Pulmonary function testing $\stackrel{\Phi}{\overparen{D}}$ showed a restrictive ventilatory defect and a re- $\mathbb{\mathbb { D }}$ duced transfer factor (Table). A bronchogram $\frac{\Omega}{O}$ showed peripheral cystic bronchiectasis in the 


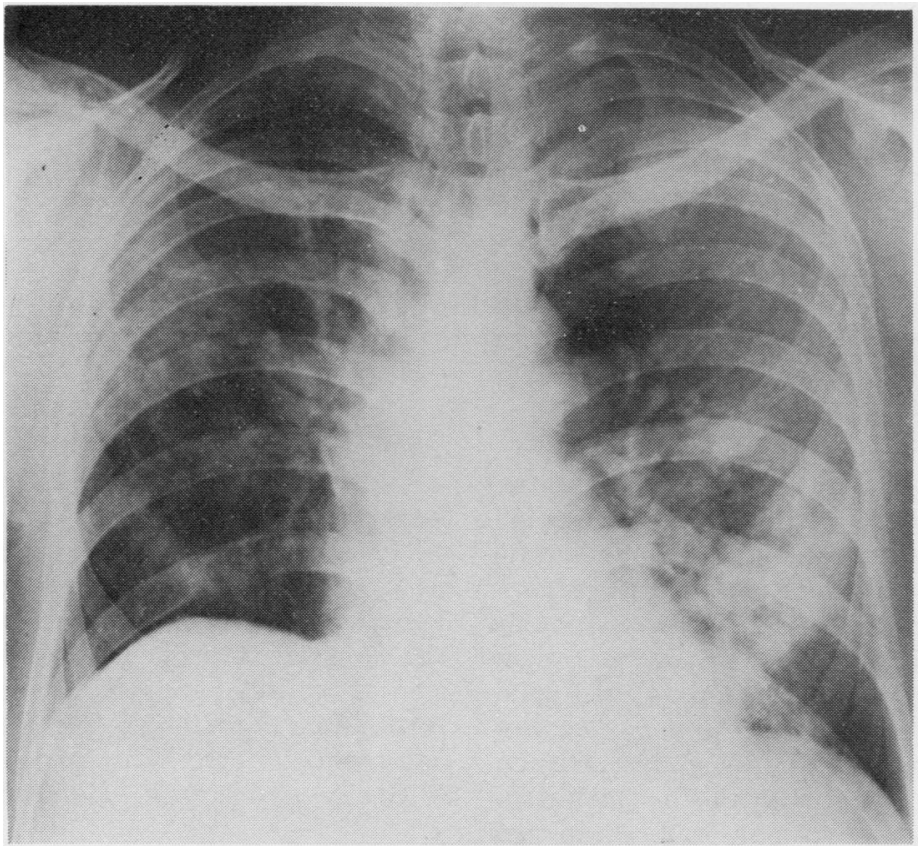

FIG. 1. Case 1. Postero anterior chest radiograph showing an alveolar filling lesion confluent through the left lung and right mid zone.

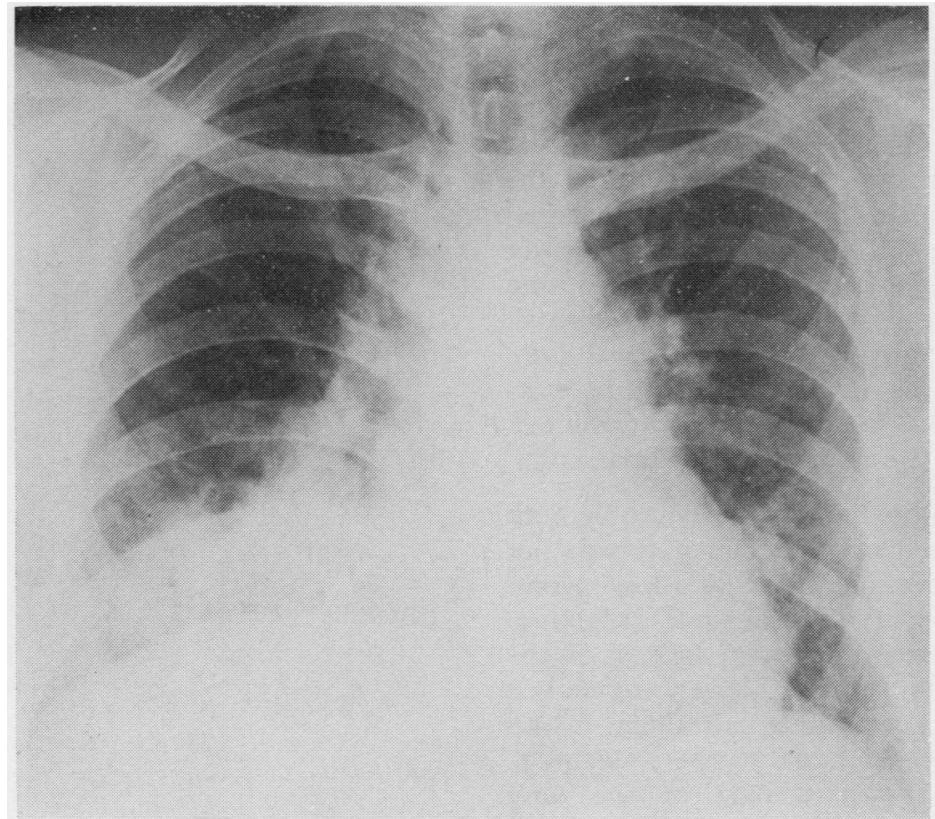

FIG. 2. Case 1. PA chest radiograph showing clearing of left side with shadowing now in the right lower zone. 
T A B L E

\begin{tabular}{|c|c|c|c|c|c|c|c|c|c|}
\hline Case & Date & $\operatorname{FEV}_{1}(\mathrm{l})$ & $\mathrm{VC}(1)$ & $\frac{\text { FEV }_{1}}{\text { VC }}$ & $R V(l)$ & FRC(l) & TLC(l) & $\underset{\left(\mathrm{mmol} \mathrm{min}^{-1}\right.}{\left.\mathrm{TPa}^{-1}\right)}$ & $\underset{\left(1 \mathrm{kPa}^{-1}\right)}{\text { Compliance }}$ \\
\hline 1 & $\begin{array}{l}11 \text { Oct '68 } \\
6 \text { Apr'69 }\end{array}$ & $\begin{array}{l}1 \cdot 6(44) \\
1.9(53)\end{array}$ & $\begin{array}{l}2 \cdot 5(55) \\
3 \cdot 0(66)\end{array}$ & $64 \%$ & $\begin{array}{l}1 \cdot 2(59) \\
1.8(90)\end{array}$ & $\begin{array}{l}1 \cdot 8(50) \\
2 \cdot 4(67)\end{array}$ & $\begin{array}{l}3 \cdot 7(55) \\
4 \cdot 8(71)\end{array}$ & $\begin{array}{l}7 \cdot 7(74) \\
9 \cdot 4(90)\end{array}$ & E \\
\hline 2 & 24 Aug '70 & $1 \cdot 3(45)$ & $2 \cdot 1(47)$ & $62 \%$ & $2 \cdot 1(137)$ & $2 \cdot 3(66)$ & $4 \cdot 2(76)$ & $5 \cdot 0(55)$ & $1 \cdot 5$ \\
\hline 3 & $19 \mathrm{Dec}$ '69 & $1 \cdot 9(63)$ & $3 \cdot 0(69)$ & $63 \%$ & $2 \cdot 7(113)$ & $3 \cdot 7(84)$ & $5 \cdot 7(85)$ & $5 \cdot 7(63)$ & $1 \cdot 1$ \\
\hline 4 & 14 July '70 & $2 \cdot 9(74)$ & $4 \cdot 8(96)$ & $60 \%$ & $2 \cdot 5(107)$ & $4 \cdot 5(98)$ & $7 \cdot 3(100)$ & $7 \cdot 7(69)$ & $1 \cdot 2$ \\
\hline
\end{tabular}

Figures in parentheses indicate percentage of predicted value.

${ }^{1}$ Multiply by 2.9 to convert to $\mathrm{ml} \mathrm{min}^{-1} \mathrm{mmHg}^{-1}$.

${ }^{2}$ Divide by 10 to convert to $1 \mathrm{CmH}_{2} \mathrm{O}^{-1}$.

right upper lobe, but all other investigations, including a liver biopsy, were normal. No precipitating antibody was detected to a TDI-albumin preparation nor to Aspergillus fumigatus, Micropolyspora, Thermoactinomyces vulgaris, mouldy hay extract, whole budgerigar extract, budgerigar serum, egg, and droppings, pigeon serum, yolk, and droppings, Bacillus subtilis, Candida albicans, 'air-conditionitis' organism or house dust extract. No haemagglutinating antibody to the TDI-albumin preparation, using formalinized sheep red blood cells, was found. Intradermal TDI albumin injection produced a positive reaction at three hours, lasting 24 hours, but this did not differ from the reaction in a control individual. Intradermal tests to $A$. fumigatus were negative immediately and at 4 hours.

Open lung biopsy At right thoracotomy the lung was found to be adherent, especially over the upper lobe and the apical segment of the lower lobe. The whole of the apical segment of the lower lobe was replaced by firm fibrous tissue. There were a few nodules in the rest of the lower lobe. The upper lobe was non-pigmented and bronchiectatic. The middle lobe felt normal. There were enlarged lymph nodes at the hilum. Biopsy specimens were taken from the most normal area of the lung, from the apical segment of the lower lobe, and from one of the nodular areas.

Pathology The histopathology was variable both from one part of a biopsy specimen to another and between the three sites. This variation encompassed appearances regarded as acute inflammation on the one hand and end-stage fibrosis on the other. Areas of the sections closely mimicked various pulmonary conditions, although in no place was there evidence of coal-workers' pneumoconiosis. The most normal part of the lung showed diffuse interstitial disease with thickening of the interalveolar septa partly from increase in collagen and partly from an interstitial mononuclear infiltrate.

No epithelial tubercles were found but there was a suggestion of accentuation of the pathological process in the centre of the lobules around the respiratory bronchioles. There was increased smooth muscle around the alveolar ducts and respiratory bronchioles (Fig. 3). Another appearance encountered was of alveolar sacs being filled by eosinophilic material in haematoxylin

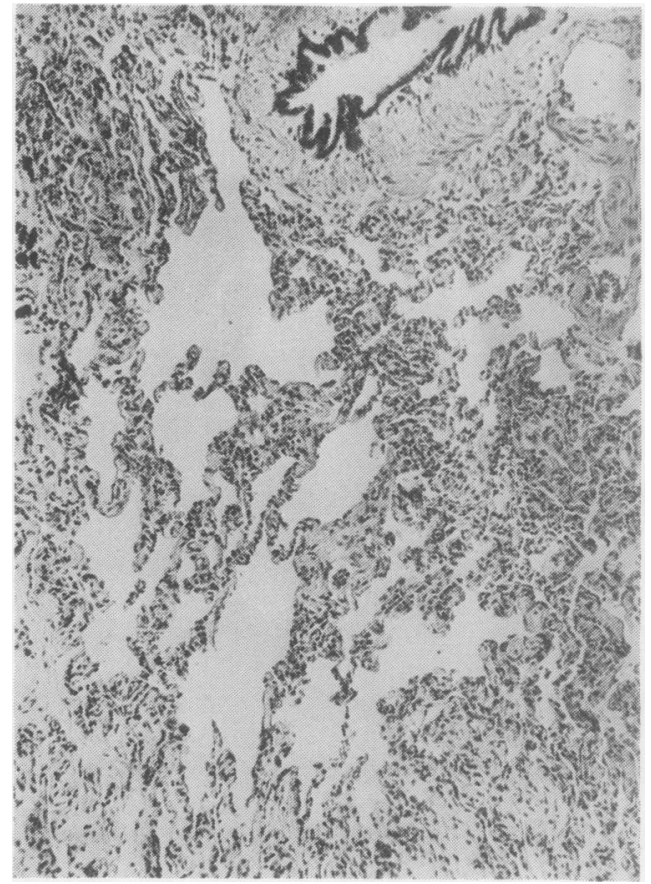

FIG. 3. Case 1. Shows thickening of interalveolar septa partly from increased collagen and partly from a mononuclear infiltrate. There is increased smooth muscle around respiratory bronchioles and alveolar ducts (Haematoxylin and eosin $\times 90$ ). 
and eosin stains (Fig. 4), bearing a superficial resemblance to alveolar proteinosis, but special stains showed the material to consist of a fine fibrous network. This area too showed thickening of interalveolar septa. Special stains revealed no bacteria, fungi or Pneumocystis carinii. An adjacent area showed a fine collagenous thickening with mononuclear leucocytes in the alveolar wall, and contributing to the cellularity of the interalveolar septum there was hyperplasia of the lining alveolar epithelial cells (Fig. 5). In other areas alveolar spaces were filled with large mononuclear cells, an appearance similar to that of desquamative interstitial pneumonitis of Liebow (Fig. 6). Other features were a heavy infiltrate of eosinophilic polymorphonuclear cells in interalveolar septa and contributing to intra-alveolar cellular exudate (Fig. 7); areas of protein-rich oedema and lymphocytic foci were also present. These latter appearances resembled those previously encountered in an inadvertently resected consolidated segment in a patient suffering from allergic bronchopulmonary aspergillosis. It was suggested that the whole picture represented a

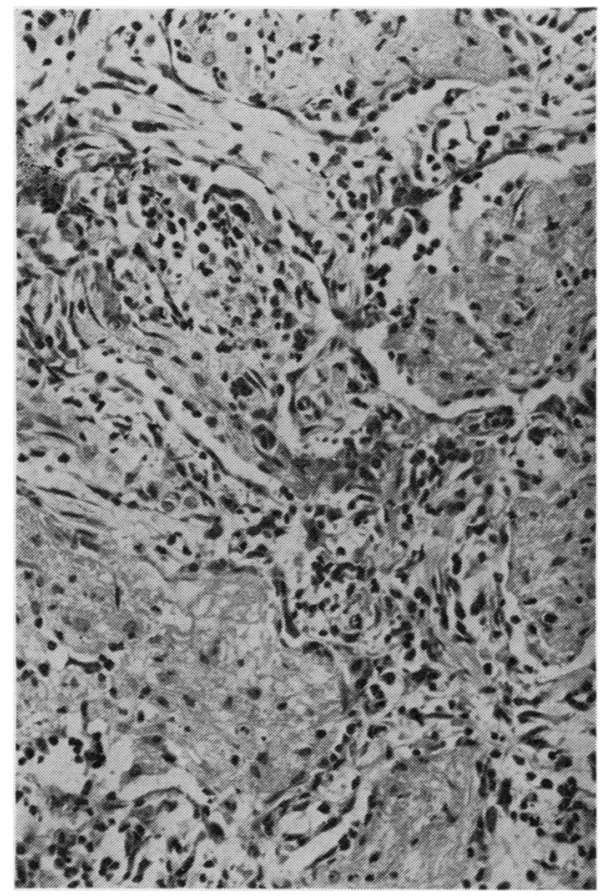

FIG. 4. Case 1. Thickening of interalveolar septa and intra-alveolar fibrinous exudate in which an occasional mononuclear cell can also be seen $(H$ and $E$ $\times 220)$.

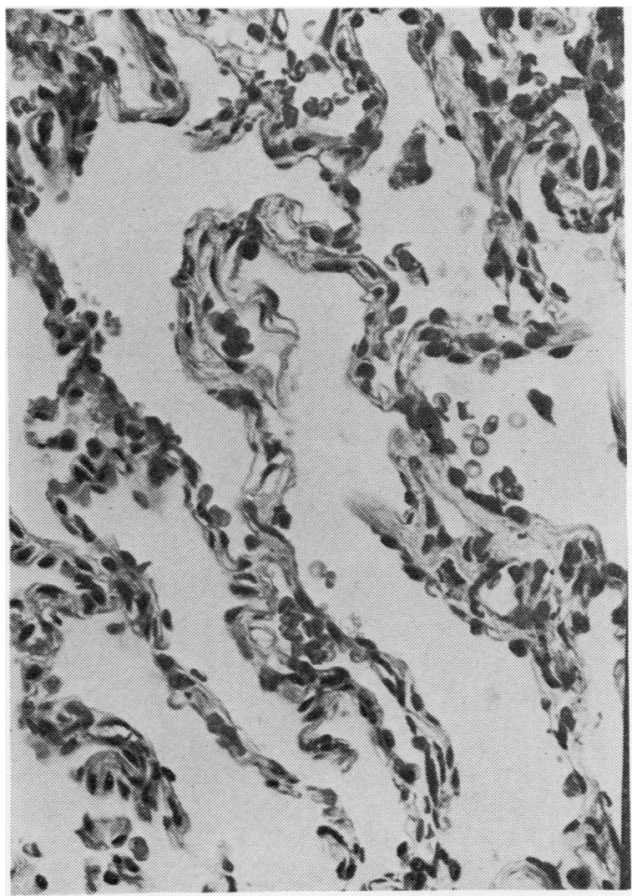

FIG. 5. Case 1. Fine collagenous thickening with mononuclear cells in the alveolar wall ( $H$ and $E \times 350)$.

hypersensitivity pulmonary response to an inhaled allergen.

Progress The patient was started on prednisone, $20 \mathrm{mg}$ daily, in January 1969. This produced a marked improvement in the chest radiograph (Fig. 8, after six months on steroids) and pulmonary function (Table). Three months after this he returned to work on a different process, but within $180 \mathrm{~m}$ of the polyurethane foam production building. Subsequent attempts on two occasions to discontinue steroids have produced increased exertional dyspnoea and malaise, significant falls in transfer factor, and recurrent radiographic changes (Fig. 9).

CASE 2 A 50-year-old man started work in March 1964 as a maintenance fitter in a factory producing polyurethane foam. He came into frequent contact with TDI over the next two years but only occasionally noticed mild chest tightness, relieved by breathing fresh air. On 26 June 1966 he was exposed to a large spill of TDI and shortly afterwards developed severe dyspnoea with wheezing and a productive cough. He remained off work for a further six months because of continuing 


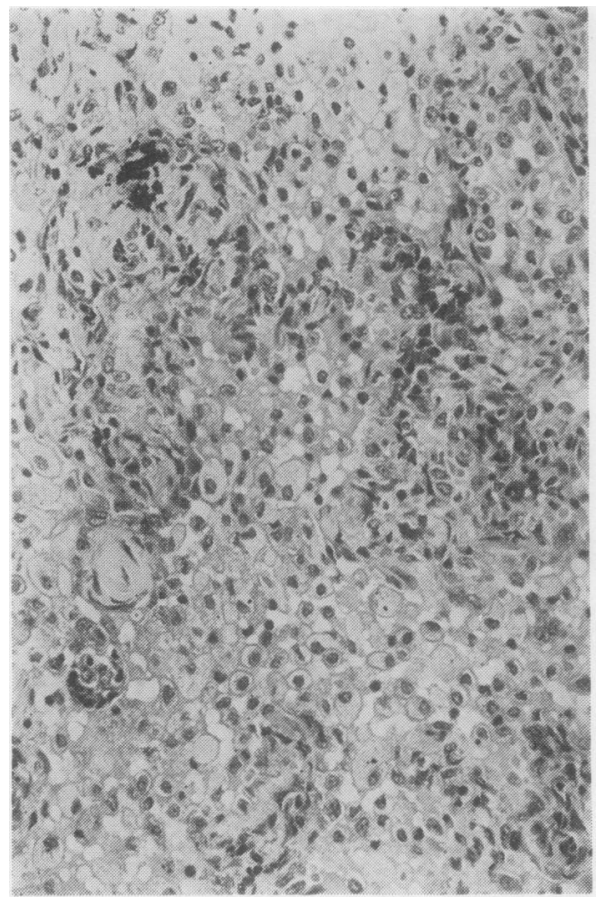

FIG. 6. Case 1. Alveolar spaces filled with large mononuclear cells resembling desquamative interstitial pneumonia ( $H$ and $E \times 220$ ).

dyspnoea. After his return to work in a different department, but still in fairly close proximity to TDI in low concentration, the dyspnoea recurred after a few days and he has not worked since that time, complaining of severe dyspnoea, without wheezing, on slight exertion. There was no past nor family history of chest disease or allergy. There was no blood nor sputum eosinophilia and all chest radiographs have been normal. In July 1966 his VC was $31 \%$ of predicted. More complete pulmonary function studies were carried out in September 1969 (Table) and showed a restrictive pattern with low compliance and transfer factor and moderate airways obstruction.

CASE 3 A 61-year-old man, a paint sprayer for 43 years, first started to use a polyurethane paint (thought to contain HDI) in June 1966. Within hours he complained of sweating and wheezing. He used a mask, but these symptoms continued on re-exposure for the next six months until he discontinued paint spraying in November 1966. For the following two and a half years he came into occasional contact with fumes associated with polyurethane paint spraying and even this contact induced similar symptoms. Since then he has had no contact whatsoever with isocyanates but has noticed non-wheezing dyspnoea on exertion which has caused him to curtail his activities considerably. Chest radiographs were normal. Pulmonary function testing showed moderate airways obstruction with reduced transfer factor and compliance (Table) suggestive of pulmonary fibrosis.

CASE 4 A 46-year-old male maintenance fitter presented complaining of effort dyspnoea increasing over one year. The onset of his symptoms was associated with an episode at work while repairing a TDI tank. A burst pipe caused flooding with TDI, and in order to release himself he had to remove his protective mask leading to direct exposure to fumes. This produced almost immediate extreme dyspnoea. He was forced to return to the tank on four occasions to complete repairs with re-exposure to TDI and resulting dyspnoea on each occasion. Two months later a similar accident led to a further exposure and dyspnoea. These episodes occurred in 1969 and,

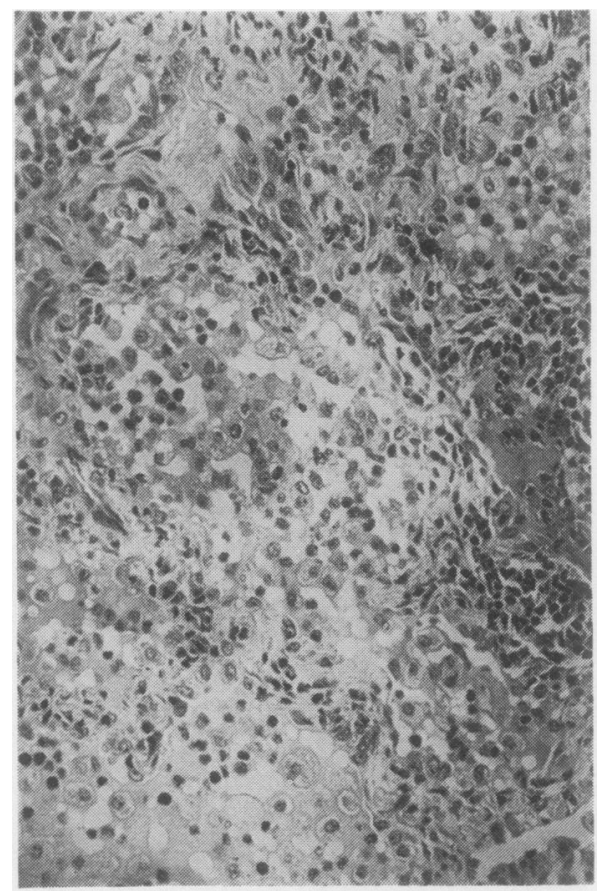

FIG. 7. Case 1. Foci of lymphocytes and polymorphonuclear leucocytes, which were all eosinophils, present in interalveolar septa and together with macrophages and desquamated alveolar epithelial cells within alveolar sacs $(H$ and $E \times 220)$. 


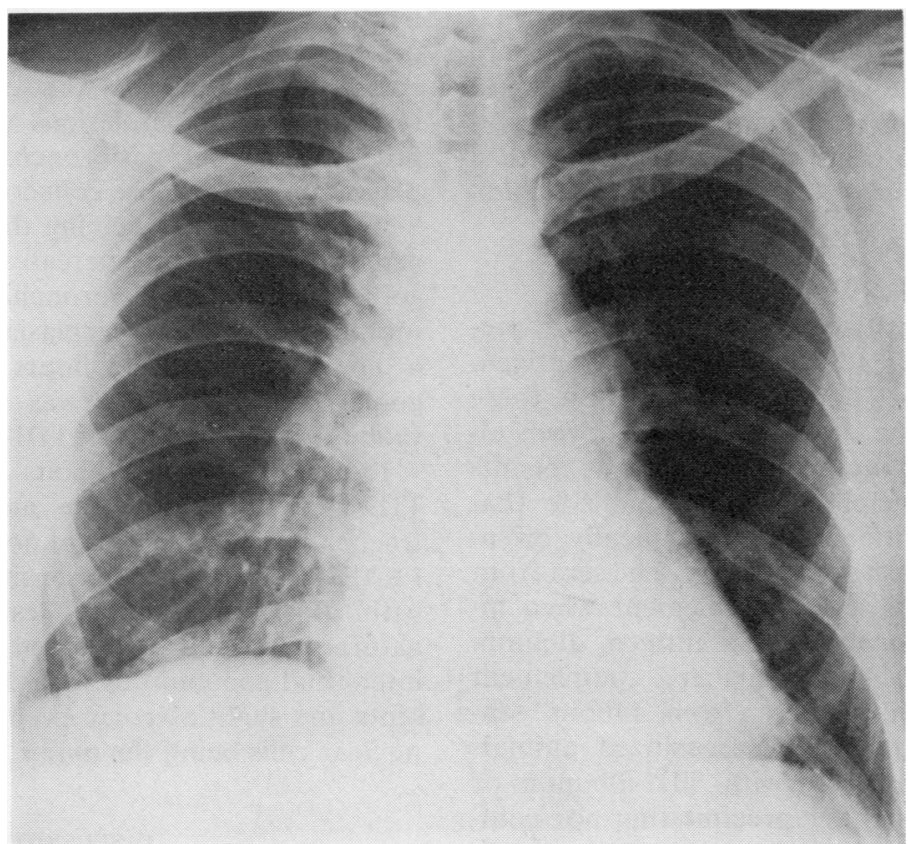

FIG. 8. Case 1. PA chest radiograph after six months' steroid therapy showing clear lung fields, the changes at the right costophrenic angle being due to thoracotomy.



FIG. 9. Case 1. PA chest radiograph showing recurrence of shadowing in right mid zone on withdrawal of steroids. 
when seen in 1971, he complained that minimal effort led to severe non-wheezing dyspnoea. There was again no evidence of allergy and the chest radiograph was normal. Pulmonary function testing showed moderate airways obstruction with a reduced transfer factor and compliance (Table).

\section{RESULTS OF ANIMAL EXPERIMENTS}

SEROLOGY All sensitized rabbits produced precipitating antibodies to their respective antigen, although in agar gel double diffusion tests there appeared to be some cross-reactivity between albumin and TDI-albumin. However, the results of quantitative precipitin analysis indicate that the majority of antibody was specifically orientated against the sensitizing antigen. The sera from all sensitized rabbits fixed complement when incubated with the corresponding antigen, albumin antisera having slightly higher complement fixation titres than antisera from rabbits sensitized with TDI-albumin. Unsensitized animals challenged endotracheally with TDI-albumin or albumin produced neither precipitating nor complement fixing antibodies against the corresponding antigen, blood being taken at death or 18 hours or 6 days after challenge.

SKIN TESTING Reddened wheals were produced at the site of injection of TDI-albumin after 4 to 24 hours with maximum intensity at 4 to 8 hours. Albumin elicited weakly positive skin tests in three out of four rabbits sensitized to TDI-albumin at similar times after injection. There were no delayed responses. Both antigens produced negative results in unsensitized animals; all animals tested with saline were negative.

PATHOLOGY Unsensitized rabbits receiving the TDI-albumin antigen developed mainly interstitial lung changes with some migration of neutrophils and a few foamy macrophages; alveolar capillaries were congested.

Patchy interstitial changes were also seen in sensitized rabbits after challenge with TDI-albumin. There was marked migration of neutrophils through thickened pulmonary arteries and oedema in peribronchial lymphoid tissue. Six days after challenging sensitized rabbits with TDI-albumin there were extensive areas of consolidation with necrosis, and in the parenchyma between necrotic areas were interstitial inflammatory changes, pulmonary oedema, epithelial metaplasia, some vasculitis (thickening of arterial walls and endothelial neutrophil cuffing), and in places epithelioid giantcell accumulations around irregularly shaped eosinophilic material. Also observed were a few residual bronchiolar lesions with neutrophils still present, residual peribronchial lymphoid hyperplasia, and a few loose collections of macrophages. Sensitized rabbits receiving the TDI-albumin antigen also developed increases in the number of goblet cells on the bronchial and bronchiolar intima, goblet-cell hyperplasia being more marked 6 days rather than 18 hours after challenge. No goblet cell hyperplasia was seen in unsensitized rabbits challenged with TDI-albumin.

Lungs of control rabbits sensitized by either TDI-albumin or albumin and challenged endotracheally with saline were noticeably undamaged. Further control rabbits sensitized and challenged with albumin produced lesions of a different nature from those obtained with TDI-albumin, interstitial pneumonitis with thickening of alveolar septa and slight alveolar exudation of large mononuclear cells being the major lesions observed.

\section{DISCUSSION}

Isocyanates are strongly irritant substances which in practice mainly affect the respiratory system. The majority of previous reports have pointed out the ability of inhaled isocyanates to produce airways obstruction (Fuchs and Valade, 1951; Trenchard and Harris, 1963). Some of these cases appeared to follow exposure to relatively high concentrations (Woodbury, 1956) while in others the reactions occurred after exposure to very low concentrations (Brugsch and Elkins, 1963; Silver, 1963; Dodson, 1966). In the cases with heavy exposure it is conceivable that a chemical irritant effect on the bronchi produced mucosal oedema and bronchospasm, but when previously exposed workers develop wheezing within seconds of being exposed to low concentrations it is considered that a hypersensitivity mechanism must also be involved.

In animals it has been shown that injection of TDI-protein conjugates results in a circulating antibody directed against the TDI determinant (Scheel et al., 1964). These workers also showed a circulating antibody response in rabbits to prolonged inhalation of TDI vapour. We have used the same methods in our rabbit experiments with similar results. Whether the antibodies found are due specifically to TDI or to TDI-denatured protein cannot be determined from these experiments. Stevens and Palmer (1970) investigated the effect of exposure of guinea-pigs and rhesus monkeys to 
atmospheres of TDI at various concentrations. They did not find an allergic mechanism to explain the sensitivity of the respiratory system and they concluded that the value of investigative work in this field was greatly limited by the complex analytical problems encountered with TDI atmospheres. Bruckner et al. (1968) showed evidence of sensitization in man by demonstrating lymphocyte transformation in sensitized individuals induced by TDI-human serum albumin conjugate. Taylor (1970) demonstrated that exposure to TDI vapour may give rise to circulating antibodies in man, but the aetiological relationship between these and symptoms of clinical sensitivity remains to be investigated.

There has been one report of pulmonary opacities resulting from diisocyanate exposure (Blake et al., 1965): four cases were described of dyspnoea and cough following exposure to TDI with changes of consolidation on the chest radiographs. Details of pulmonary function are not given. Each patient improved on complete removal from exposure, one relapsing on re-exposure.

Our four cases are the first described to have developed impairment of respiratory function other than airways obstruction after isocyanate exposure. This potentially more serious lesion of interstitial pneumonitis occurred in two after heavy exposure but in two after much lighter exposure, and in all patients symptoms and physiological evidence of disease persisted after removal from other than 'neighbourhood' exposure. The likelihood that the disease in these patients was due to isocyanates is supported by the detailed histological evidence suggesting inhalational allergic pneumonitis in case 1 and its similarity to that induced experimentally by challenge in animals. Moreover, all our patients also had the more usual pattern of airways obstruction, suggesting that both the bronchi and the interstitial tissues were involved, a feature seen in other conditions grouped as allergic alveolitis. However the difficulty of being certain of the diagnosis clinically is shown by the negative immunological tests in case 1 and the normal radiographs in the other patients.

Rabbits sensitized to produce precipitating antibodies against TDI-albumin and challenged with the same antigen developed lesions similar in nature to those observed in rabbits after the production of a type III response by consecutive endotracheal depositions of heterologous serum (Edwards, 1974). Lesions particularly characteristic of the Arthus response included polymorphonuclear cellular exudation, peribronchial lymphoid hyperplasia, interstitial pneumonitis, and pulmonary oedema. Positive skin tests 4 to 8 hours after injecting TDI-albumin intradermally also suggested a type III involvement.

Goblet-cell hyperplasia, an early indication of bronchitis, was observed in all rabbits sensitized and challenged with TDI-albumin. Bronchitic lesions have been demonstrated in experimental animals after repeated inhalation of low (Niewenhuis et al., 1965) and high (Duncan et al., 1962) concentrations of TDI. Direct chemical injury was thought to be responsible but since gobletcell hyperplasia was observed to a much lesser degree in unsensitized rabbits challenged with TDI-albumin it seems possible that an immune mechanism may be involved in the production of this lesion. Our animal results therefore raise the question whether pulmonary hypersensitivity reactions themselves may result in permanent hyperplasia of mucus-secreting apparatus and lead to clinical chronic bronchitis in man. The TDI-albumin antigen used experimentally is unlikely to be the same as that produced in the body by combination between TDI vapour and body proteins. It is considered more likely that TDI reacts with protein of the mouth, nose, and upper respiratory tract and that particles of conjugated protein are then inhaled. Whether such an 'antigen' would produce lesions in the lung similar to those obtained with TDI-albumin conjugate requires further study. There were no eosinophilic responses or immediately positive skin tests in the experimental animals and it therefore seems unlikely that type I mediated reactions to TDI-albumin conjugate occurred in these. Type I allergy to TDI may, of course, be confined to the human species.

One should be cautious in comparing the experimental situation with that in patients because of species differences, unnatural antigen conjugates, and dosage differences. We have, however, shown evidence of a type III response to challenge in sensitized rabbits and also that lesions other than bronchial can occur in man following exposure to isocyanates. We postulate that isocyanate inhalation in some situations may give rise to a type III immune response in man which may produce interstitial lung disease.

Isocyanate workers are at present routinely examined for evidence of airways obstruction. If their lung volumes and gas transfer factors were also measured it is possible that more cases such as ours would be found, and that some of these patients may be helped by corticosteroids. 


\section{REFERENCES}

Adams, W. G. F. (1970). Lung function of men engaged on the manufacture of T.D.I. Proceedings of the Royal Society of Medicine, 63, 378.

Blake, B. L., Mackay, J. B., Rainey, H. B., and Weston, W. J. (1965). Pulmonary opacities resulting from di-isocyanate exposure. Journal of the College of Radiology of Australasia, 9, 45.

Boyden, S. V. (1951). The adsorption of proteins on erythrocytes treated with tannic acid and subsequent hemagglutination by antiprotein sera. Journal of Experimental Medicine, 93, 107.

Bradstreet, C. M. P. and Taylor, C. E. D. (1962). Technique of complement-fixation test applicable to the diagnosis of virus diseases. Monthly Bulletin of the Ministry of Health and Public Health Laboratory Service, 21, 96.

Bruckner, H. C., Avery, S. B., Stetson, D. M., Dodson, V. N., and Ronayne, J. J. (1968). Clinical and immunologic appraisal of workers exposed to diisocyanates. Archives of Environmental Health, 16, 619.

Brugsch, H. G. and Elkins, H. B. (1963). Toluene di-isocyanate (T.D.I.) toxicity. New England Journal of Medicine, 268, 353.

Cotes, J. (1968). Lung Function Assessment and Aplication in Medicine, 2nd edition. Blackwell Scientific Publications, Oxford.

Dodson, V. N. (1966). Asthma and T.D.I.-exposure. Journal of Occupational Medicine, 8, 81 .

Duncan, B., Scheel, L. D., Fairchild, E. J., Killens, R., and Graham S. (1962). Toluene diisocyanate inhalation toxicity: pathology and mortality. American Industrial Hygiene Association Journal, 23, 447.

Edwards, J. H. (1974). Experimental immunopathology with specific antigenic fractions. In Proceedings of the IVth International Symposium on A spergillosis and Farmer's Lung, Davos, edited by de Haller and R. F. Suter. Hans Huber, Vienna.

Fuchs, S. and Valade, P. (1951). Étude clinique et expérimentale sur quelques cas d'intoxication par le desmodur $\mathrm{T}$. (diisocyanate de toluylène 1-2-4 et 1-2-6). Archives des Maladies Professionelles de Médecine du Travail et de Sécurité Sociale, 12, 191 .
Hill, R. N. (1970). A controlled study of workers handling organic diisocyanates. Proceedings of the Royal Society of Medicine, 63, 375.

Kabat, E. A. (1961). Kabat and Meyer's Experimental Immunochemistry, 2nd edition. Thomas, Springfield, Illinois.

Niewenhuis, R., Scheel, L. D., Stemmer, K., and Killens, R. (1965). Toxicity of chronic low level $\overrightarrow{0}$ exposures to toluene diisocyanate in animals. American Industrial Hygiene Association Journal, 26, 143.

Ouchterlony, Ö. (1953). Antigen-antibody reactions in gels. IV. Types of reactions in coordinated systems of diffusion. Acta Pathologica et Microbiologica Scandinavica, 32, 231.

Peters, J. M. (1970). Cumulative pulmonary effects in workers exposed to tolylene diisocyanate. Pro- ceedings of the Royal Society of Medicine, 63, 음 372.

Rowe, D. S. and Fahey, J. L. (1965). A new class of $D$ human immunoglobulins. II. Normal serum IgD. Journal of Experimental Medicine, 121, 185.

Scheel, L. D., Killens, R., and Josephson, A. (1964). Immunochemical aspects of toluene diisocyanate $\sigma$ (T.D.I.) toxicity. American Industrial Hygiene Association Journal, 25, 179.

Silver, H. M. (1963). Toluene diisocyanate asthma. Archives of Internal Medicine, 112, 401.

Stevens, M. A. and Palmer, R. (1970). The effect of tolylene diisocyanate on certain laboratory animals. Proceedings of the Royal Society of Medi- $\overrightarrow{\bar{O}}$ cine, 63, 380.

Taylor, G. (1970). Immune responses to tolylene diisocyanate (T.D.I.) exposure in man. Proceedings of the Royal Society of Medicine, 63, 379.

Trenchard, H. J. and Harris, W. C. (1963). An outbreak of respiratory symptoms caused by toluene di-isocyanate. Lancet, 1, 404.

Woodbury, J. W. (1956). Asthmatic syndrome follow- 윽 ing exposure to tolylene diisocyanate. Industrial Medicine and Surgery, 25, 540.

Requests for reprints to: Dr. A. Seaton, Asthma Research Unit, Sully Hospital, Penarth, South Glamorgan CF6 2YA. 